\title{
STABILITY OF CART PEPTIDE EXPRESSION IN THE NUCLEUS ACCUMBENS IN AGING
}

\author{
Simon Armbruszt, ${ }^{1}$ MÁria Figler ${ }^{1}$ and Hajnalka ÁbrahÁm ${ }^{2 *}$ \\ ${ }^{1}$ Institute of Nutritional Sciences and Dietetics, Faculty of Health Sciences, University of Pécs, \\ Pécs, Hungary \\ ${ }^{2}$ Central Electron Microscopic Laboratory, Faculty of Medicine, University of Pécs, Pécs, Hungary
}

(Received: February 6, 2014; accepted: August 6, 2014)

\begin{abstract}
Aging is accompanied by changes of several anorexigenic and orexigenic neuropeptides expressed in various brain areas that control food intake and these changes correlate with senescent anorexia. During aging expression of cocaine- and amphetamine-regulated transcript (CART) peptide was reported to be reduced in the hypothalamic nuclei related to food intake. Although CART peptide is abundant in the nucleus accumbens that also plays a crucial role in the food intake regulation, no data is available about the CART peptide expression in this region through aging. In the present study, CART peptide immunoreactivity was compared in the nucleus accumbens of young adult (4- and 7-month-old) middle-aged (15-month-old) and aging (25-32-month-old) Long-Evans rats. The density of CART-immunoreactive cells and axon terminals in the nucleus accumbens was measured with computer-aided densitometry. CART-immunodensity was similar in the old rats and in the younger animals without significant difference between age groups. In addition, no gender-difference was observed when CART-immunoreactivities in the nucleus accumbens of male and female animals were compared. Our results indicate that CART peptide expression in the nucleus accumbens is stable in adults and does not change with age.
\end{abstract}

Keywords: Food intake - anorexigenic peptide - reward system - age-related - densitometry

\section{INTRODUCTION}

Food intake and weight gain are precisely regulated mechanisms that show agerelated changes. The positive energy balance of young animals supports anabolic mechanisms, but with age the catabolic processes become predominating. In middleaged rodents age-related obesity has been observed, while in old animals reduction of food intake and the loss of body weight results in a state of anorexia [6, 7]. The reason for the decreased food intake is multi-factorial relating to both peripheral and central mechanisms. Many central mediators including peptides synthesized by neurons of the central nervous system control appetite.

Alteration of expression and effectiveness of several neuropeptides including orexigenic and anorexigenic peptides were shown to correlate with changes of food

*Corresponding author; e-mail address: hajnalka.abraham@aok.pte.hu 
intake and metabolism characteristic for different age groups. The age-related alteration of cholecystokinin (CCK) sensitivity was shown throughout the lifespan: a declination of its anorexic effect was observed with age, with a consequent elevation of CCK plasma level $[4,5]$. An age-dependent effect was also observed by administration of another anorexigenic neuropeptide, the alpha-melanocyte-stimulating hormone. When intracerebroventricularly injected, it strongly suppressed food intake in young adults, becoming less effective in middle-aged groups and proved to be extremely effective in old rats [24, 25].

Decreased expression of agouti-related peptide (AgRP) and neuropeptide Y (NPY) genes was demonstrated in the hypothalamic arcuate nucleus with the age, and very old animals have shown increased sensitivity for AgRP compared to younger animals [34]. In contrast, NPY had a stronger effect on food intake in younger rats than in aged animals $[2,8]$. Another neuropeptide abundant in the hypothalamus is the cocaine- and amphetamine-regulated transcript (CART) peptide which has a strong anorexic effect $[16,17]$. Mutual interaction between CART peptide and NPY was shown and central administration of CART peptide potently suppressed feeding and blocked the increase in food intake induced by NPY [18, 32]. In contrast to the observed decrease of NPY expression in the hypothalamus of aged animals, in situ hybridization showed increased expression of CART mRNA in the arcuate nucleus [28]. Another area related to feeding and reward functions and where NPY expression found to be decreased in aged rats is the nucleus accumbens (NACC), where the number of NPY-immunoreactive neurons was reduced [23]. In the NACC, the role of CART peptide has also been proven, and CART peptide injection into the shell of the NACC has an inhibitory effect on food intake [35]. In addition to the effect of exogenous CART peptide, the NACC is abundant in CART-immunoreactive fibers and axon terminals [17]. In addition, feeding-related changes of CART expression were observed in the NACC. Fasting downregulated CART mRNA expression in control rats, while CART peptide immunoreactivity was reduced in the NACC of diabetic and obese CCK-1 receptor deficient rats $[1,35]$.

The role of the NACC in obesity and aging was also demonstrated in humans using magnetic resonance imaging (MRI) that revealed volume changes in overweighed individuals as well as in aging humans [12, 19, 21, 33].

Based on the evidences that aging and obesity influences the size of NACC, together with the role of CART peptide exerted in the NACC, we raised the question whether CART peptide expression in the NACC has been changed in aged rats. Therefore in the present study, the distribution and the intensity of CART peptide immunoreactivity in the NACC of aged Long-Evans rats were compared to that of lean, healthy younger adult animals. 


\title{
MATERIALS AND METHODS
}

\begin{abstract}
Animals
In our study, 17 Long-Evans rats were used. Both male and female adult and aged animals were included in this study, and the animals were classified in three age groups. Groups containing young adult (4 months old males, $\mathrm{n}=4$, weighing $324 \pm 20.22$ g; 7 months old females, $n=3$, weighing $220 \pm 16.01$ g), middle-aged adult ( 15 months old females, $\mathrm{n}=3$, weighing $232 \pm 9.12 \mathrm{~g}$ ) and aging (25-32 months old males, $n=4$, weighing $426.6 \pm 24.94 \mathrm{~g}$, and 26-30 months old females, $\mathrm{n}=3$, weighing $271.6 \pm 17.44 \mathrm{~g}$ ) rats were formed. Animals were housed individually and kept on a 12:12-h light-dark cycle receiving ad libitum tap water and pelleted rat chow. Before their sacrifice, the amount of the consumed food by the young adult and aging animals was measured for a month. All protocols used in the present study were conducted in accordance with the National Institute of Health Guide for the Care and Use of Laboratory Animals (NIH Publications No. 88-2959, 2002), as well as with the EU Directive 2010/63/EU for animal experiments.
\end{abstract}

\section{Immunohistochemistry}

Since plasma and brain levels of CART peptide exhibit a diurnal variation [31], rats were sacrificed at the same time in the afternoon (between 2 and 4 p.m.). Animals were terminally anaesthetized with pentobarbital (Nembutal $100 \mathrm{mg} / \mathrm{kg}$ body weight), then transcardially perfused with $0.1 \mathrm{M}$ phosphate buffer (PB, $\mathrm{pH} 7.4$ ), followed by perfusion of $4 \%$ formaldehyde in $\mathrm{PB}$. The brains were removed from the skull and postfixed overnight in the same fixative used for the perfusion. Following fixation, blocks containing the NACC from its rostral portion to the caudal part of the shell region (rostro-caudal Paxinos coordinates: Bregma 0.7-2.7) were cut out from the brains [22]. Free floating sections at $60 \mu \mathrm{m}$ were cut using a vibratome, then collected and processed for immunocytochemistry as described earlier [1, 3]. Briefly, after washing in $\mathrm{PB}$, sections were pretreated with a solution of $1 \%$ hydrogen-peroxide for $30 \mathrm{~min}$ to block endogenous peroxidase activity, then pre-incubated in normal horse serum (1\% in PB) containing $0.4 \%$ Triton X-100 for $1 \mathrm{~h}$. This step was followed by incubation with the primary anti-CART (55-102) antibody (Phoenix Pharmaceuticals, Burlingame, CA) diluted in PB $(1: 10,000)$ overnight at room temperature. Binding sites were visualized with biotinylated secondary antibody (1:100, Vector Laboratories, Burlingame, CA) and the avidin-biotin peroxidase detection system (1:50, Vector Laboratories, Burlingame, CA) using 3,3'-diaminobenzidine as chromogene. The sections were mounted on glass slides, air-dried, dehydrated, cleared with xylene and covered with Eukitt (Fluka). The specificity of the primary antibody was determined by the company. However, when the primary antiserum was omitted from the procedure, no staining was detected. 


\section{Quantification of intensity of CART peptide immunoreactivity}

Areas containing the NACC core and shell regions were digitally photographed with an Olympus BX51 microscope. To test the available methods for densitometry, intensity of immunostaining detected in the male animals was determined on black and white images using two different softwares, Image (an open source image processing and analyzer program written in Java and supported by the NIH, USA) and AnalySIS software (Olympus Corporation). As a validation process we compared the results obtained with the two softwares to each other. As the suitability of both software was proven, CART-immunoreactivity in the NACC of female rats was determined with ImageJ.

In each animal, measurements were made on the antero-posterior extension of the rostral NACC, in non-consecutive sections. Because CART peptide is released at the synaptic terminals [35], in the same section, white matter of the anterior commissure that lacks CART was considered as background and the staining intensity of it was measured to quantify background intensity. After the area to be measured was determined, both ImageJ and AnalySIS software took samples regularly, and measured the intensity of pixels, expressed them as numerical values. The values measured either in the NACC or in the white matter were then averaged, and the intensity of the NACC and that of the white matter was determined, respectively. The relative intensity which is the real intensity of the CART peptide immunostaining, referred in Results and Discussion as "intensity of CART-immunoreactivity" or "staining intensity", was calculated by subtracting intensity values of the NACC from intensity values of the white matter. Since the light intensity and the magnification used greatly affect the intensity values, all measurements in each rat were done using the same light and the same objective for magnification.

\section{Statistics}

After determination of intensity of immunostaining, statistical significance was assessed using Student's $t$-test for paired samples, non-parametric Mann-Whitney U test as well as one-way analysis of variance (ANOVA) with SPSS V22.0 for Windows software. All data were expressed as means $+\mathrm{SD}$, and differences were considered statistically significant if $\mathrm{p}<0.05$.

\section{RESULTS}

\section{Food consumption by young and aged animals}

When the weight of daily consumed food of the young adult and aged Long-Evans rats were compared no significant difference was observed. Young male animals eat $20.89 \pm 1.69 \mathrm{~g}$ lab chow per day, while the weight of food consumed by old male 
animals was $21.35 \pm 3.88 \mathrm{~g}$. Generally, less lab chow was consumed by the females than the males, and the young females eat more $(18.73 \pm 6.02 \mathrm{~g})$ than the aged females $(16.36 \pm 1.52 \mathrm{~g})$ but the difference was not significant. However, when the amount of daily consumed food was calculated to $100 \mathrm{~g}$ body weight, significant $(\mathrm{p}<0.005)$ age-related difference could be found in the male group as well as in the female group. Explicitly, young male animals eat more (6.44 $\pm 0.52 \mathrm{~g} / 100 \mathrm{~g}$ body weight) than aged male rats $(5.00 \pm 0.90 \mathrm{~g} / 100 \mathrm{~g}$ body weight). Similarly, younger females consumed more food per day $(8.51 \pm 2.81 \mathrm{~g} / 100 \mathrm{~g}$ body weight) than aged females $(6.02 \pm 0.52 \mathrm{~g} / 100 \mathrm{~g}$ body weight).

\section{CART peptide immunoreactivity in the nucleus accumbens}

In the forebrain including the NACC of young adult, middle-aged and elderly LongEvans male as well as female rats, the distribution of CART peptide immunoreactivity was identical to that observed previously in control rats [1, 3, 17]. Accordingly, strong CART peptide immunoreactive neurons and fibers were found in both the rostral and caudal part of the NACC in all groups of animals. Comparing the distribution and the intensity of CART peptide immunoreactivity under light microscope, no visible age-related or gender-related difference could be observed (Figs 1, 2).

\section{Quantification of CART-immunoreactivity in the nucleus accumbens}

In order to collect trustable data on CART peptide immunoreactivity for young adult, middle-aged and elderly animals, the density of the immunoreaction was measured on black and white photos of the NACC with computerized densitometry.

To validate the methods for the quantification, we used two different softwares, the Image J which is a free access software and the AnalySIS (Olympus Corporation). There were no significant differences in the intensity results when the two image processing and analyzing softwares were compared.

When the measurements of intensity of CART-immunostaining were performed on the young adult and aged male rats, no significant age-related differences were observed. The intensity of CART-immunoreactivity in the NACC of the 4 months old (21.6 \pm 7.02$)$ and $25-32$ months old (22.2 \pm 3.81$)$ rats measured with the ImageJ software was similar (Fig. 3A, Table 1). With this software, the highest intensity value was 33.76 in the young and 24.38 in the old animals, with the lowest value of 16.60 and 17.67 in the young and old rats, respectively. Similarly to the results of the ImageJ program, the AnalySIS software did not show difference between the CARTimmunoreaction in the young (57.0 \pm 5.80$)$ and in the aged $(62.3 \pm 4.17)$ animals (Fig. 3B). The highest intensity value was 61.23 in the young and 63.19 in the old ones, with a minimum value of 36.86 in the young and 53.27 in the aged rats. When the CART peptide immunoreactivity was analyzed no age-related correlation could be seen among the individuals of the group of old animals with both software. 

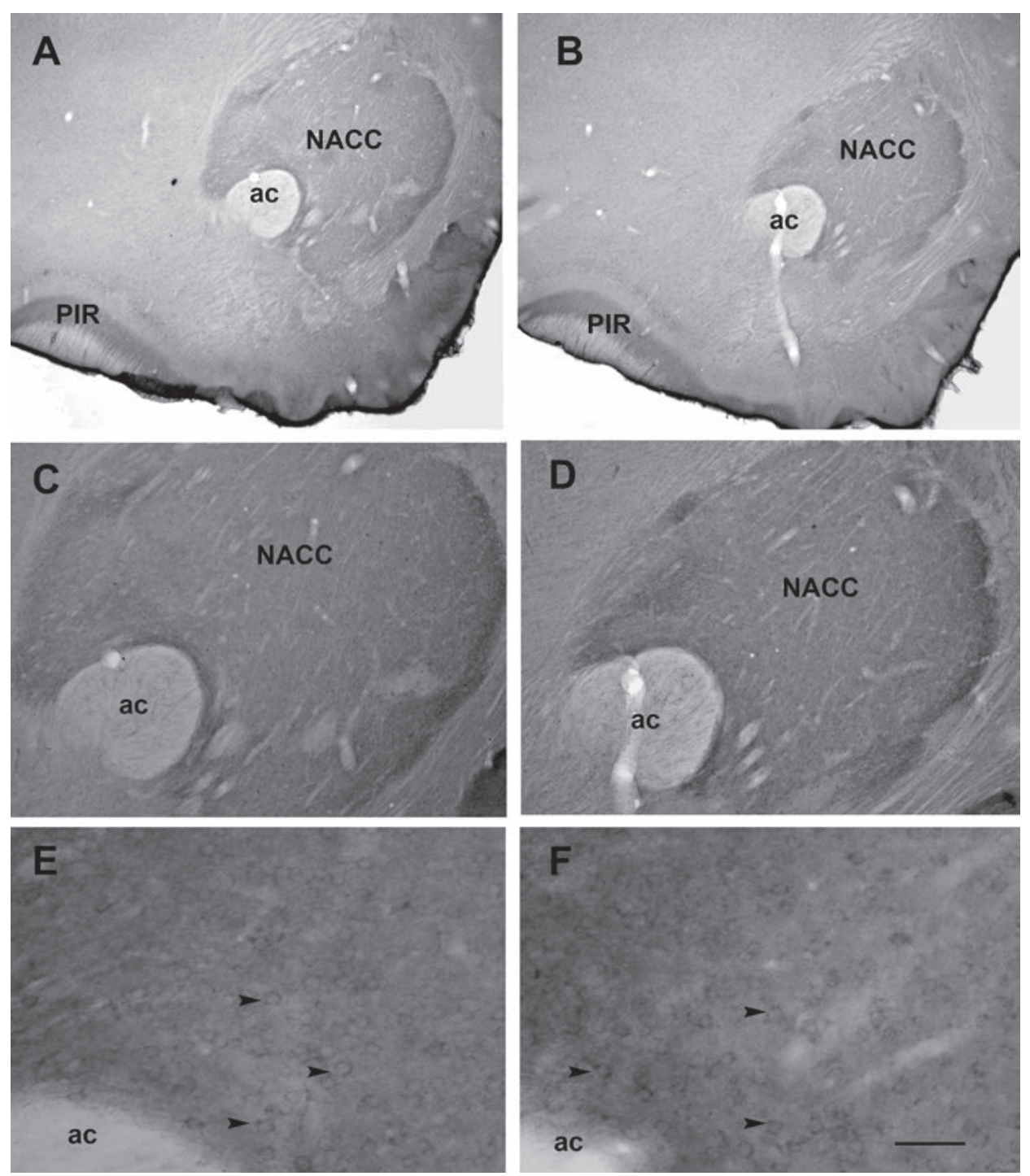

Fig. 1. Photomicorographs showing CART-immunoreactivity in the rostral portion of the nucleus accumbens (NACC) in the young adult (A, C and E) and in the aged (B, D and F) male rats. Arrowheads in E and F point to a few CART-immunoreactive cell bodies which are present in high number in the NACC. Additional abbreviations: ac, anterior commissure; PIR, piriform cortex. Scale bar: $200 \mu \mathrm{m}$ in A, B, $100 \mu \mathrm{m}$ in $\mathrm{C}, \mathrm{D}$ and $60 \mu \mathrm{m}$ in $\mathrm{E}, \mathrm{F}$ 

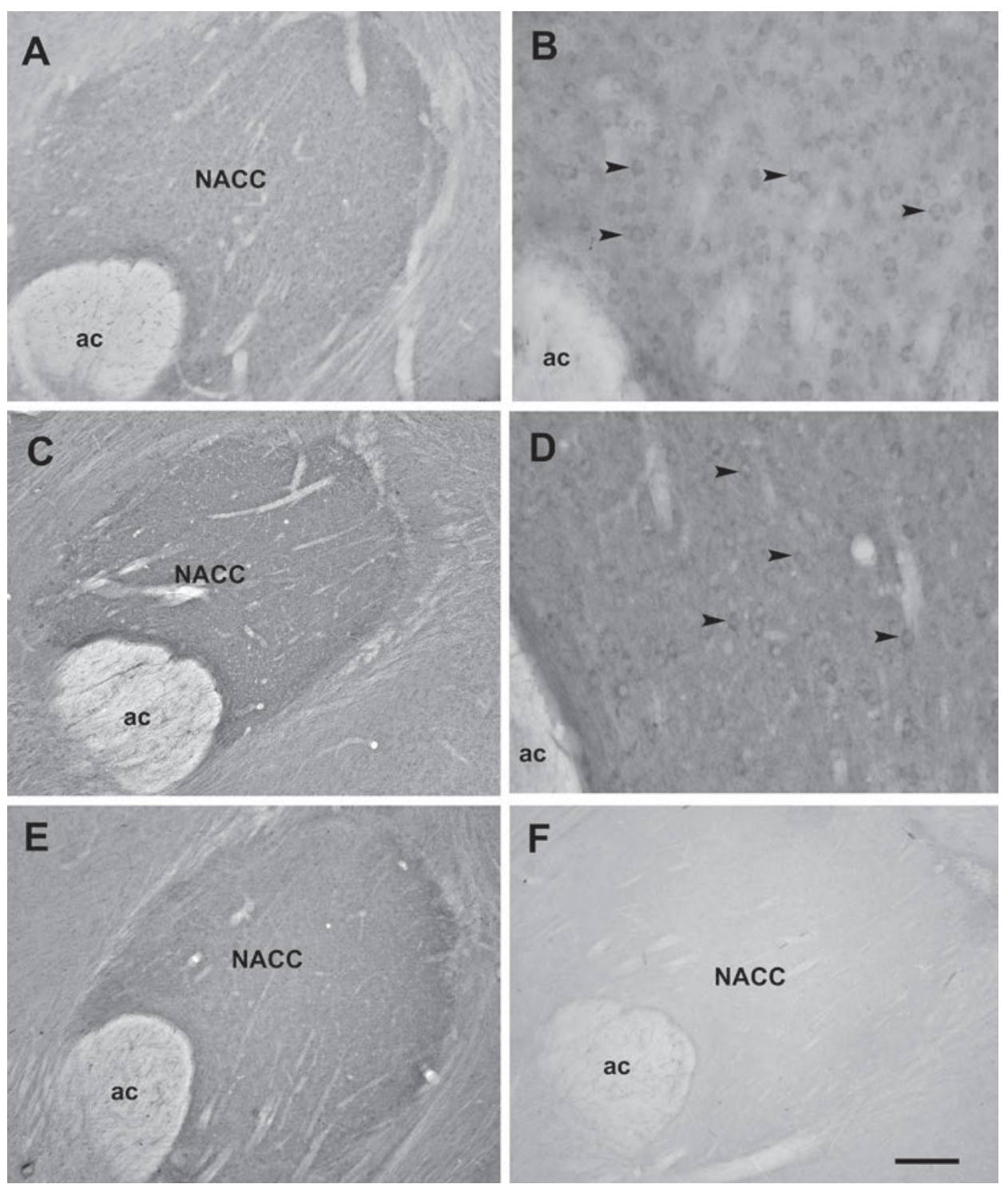

Fig. 2. Photomicorographs showing CART-immunoreactivity in the rostral portion of the nucleus accumbens (NACC) in the young adult (A, B) and in the middle-aged (C, D) an in aging (E) female rats. F demonstrates lack of CART peptide immunoreactivity in a negative control when the primary antibody was omitted from the procedure. Arrowheads in B and D indicate CART-immunoreactive cell bodies which are present in high number in the NACC. Additional abbreviation: ac, anterior commissure. Scale bar: $100 \mu \mathrm{m}$ in A, C, E and F, $60 \mu \mathrm{m}$ in B and D 
A

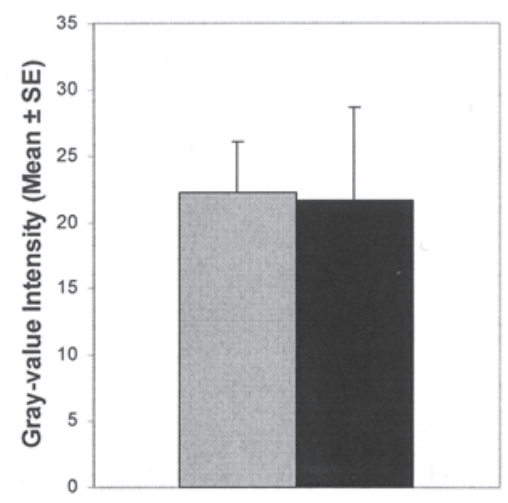

B

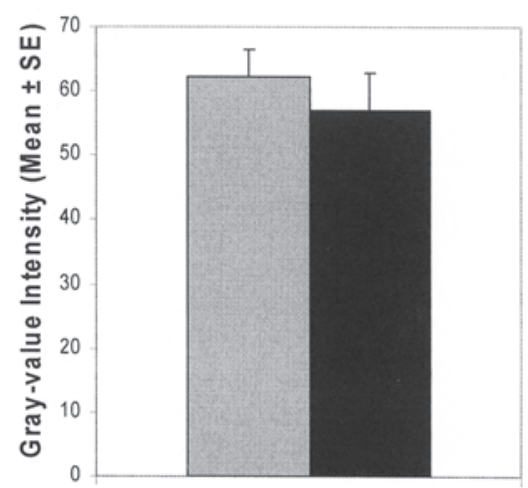

Fig. 3. Density of the CART-immunoreactivity in the nucleus accumbens measured with Image J (A) and AnalySIS (B) softwares in old (gray bars) and in young (black bars) male animals. Error bars indicate standard deviation

We could not measure significantly altered CART-immunoreaction between 25 and 32 months old male animals. In addition, we concluded that both methods are appropriate to determine CART-immunodensity in the NACC.

Next, we compared the intensity of CART-immunoreaction in the NACC of male (25-32 months old) and female (26-30 months old) elderly rats using ImageJ software. We have found no significant difference between the intensity of NACC in aging male (22.2 \pm 3.81$)$ and female rats $(19.4 \pm 1.73)$ indicating that there is no gender-related difference in the CART expression in the aged rats (Table 1). We also compared CART immuno-intensity in young male (21.6 \pm 7.02$)$ and female $(20.0 \pm 6.32)$ adult rats, and found that no significant gender-related difference can be observed in the NACC. Comparing CART expression in young $(20.0 \pm 6.32)$ middleaged (27.02 \pm 7.29$)$ and elderly (19.4 \pm 1.73$)$ females, no significant age-related difference could be observed.

Table 1

Average of CART peptide immunodensity values measured in the nucleus accumbens of rats of different age groups

\begin{tabular}{|l|c|c|}
\hline \multicolumn{1}{|c|}{ Age group } & Male & Female \\
\hline Young adult & $21.6 \pm 7.02$ & $20.00 \pm 6.32$ \\
\hline Middle-aged adult & NA & $27.02 \pm 7.29$ \\
\hline Aging adult & $22.2 \pm 3.81$ & $19.40 \pm 1.73$ \\
\hline
\end{tabular}

CART peptide immunodensity values are expressed as mean \pm SD. Immunodensity was measured with the ImageJ software. NA indicate the age group in which data is not available. 
Because of the small sample size, we have taken into consideration that our mean data are skewed, therefore we performed non-parametric Mann-Whitney U test which is less sensitive to extreme values. In addition, we have performed one-way ANOVA to compare the means of the CART-immunodensity values. Both statistic tests and a post-hoc statistical power calculation for Student $t$-test resulted non-significant differences between the examined animal groups, which indicates that CART peptide expression is stable in adults, and does not change during aging.

\section{DISCUSSION}

Despite the wide spectrum of neuropeptides that display altered expression in brain areas related to food intake through aging, no alteration of CART peptide immunoreactivity was observed in the NACC of aged Long-Evans rats when compared to young and middle-aged adults. In addition, no gender-related difference could be observed in adult and aging animals. These indicate that CART peptide expression in the NACC of lean and healthy rats is stable and does not change throughout the lifespan of animals.

\section{Technical considerations}

In order to have accurate data of the CART peptide immunodensity, measurements of the CART-immunoreaction were performed with two different softwares. The ImageJ software is an open-access image processing and analyzer program supported by the NIH (USA), while the AnalySIS software of the Olympus Corporation can be used with Olympus microscopes and digital cameras.

Both ImageJ and AnalySIS softwares gave the same results when the density of CART-immunostaining was compared in young and aged male animals suggesting that our measurements were valid, and that both softwares are adequate to evaluate immunohistochemistry for light microscopy. Differences, however, could be observed in the absolute values of the densities measured with the two different softwares, but these are related to the different programming and calibration of the intensity of pixels. When values observed with the two softwares were compared, both revealed similar results in young and aged rats indicating stable expression of CART peptide in the NACC during aging.

\section{The ages of the animals}

The ages of the old rats varied between 25 and 32 months, which correspond to the senescent stage in humans. At this age food intake declines and aging related anorexia appears in dramatic weight loss [6, 20]. However, in contrast to the long period of time when strong decrease of food consumption can be seen in humans, this time 
period is restricted to only 3 weeks before death in rats [6, 20]. Earlier than 3 weeks before death the daily food intake does not differ from that of younger rats. When calculating of the consumed food for 100 grams body weight, aged animals take up significantly less food than young rats, although the old rats were not yet in the stage of the anorexia. In contrast to the difference in food intake, the expression of CART peptide was not changed in the NACC of both male and female aged rats. However, we have to emphasize that in most of the recently published studies, that have shown age-related changes of food consumption and altered of expression of peptides linked to food intake, rats between 25-30 months of age were used [2, 6, 15, 24, 25, 29].

\section{CART peptide expression is stable through adulthood}

Hypothalamic expressions of numerous orexigenic neuropeptides such as NPY, AgRP and orexins were changed during aging, however, expression of the anorexigenic neuropeptide POMC was similar in young and old animals [13, 14, 26, 28, 34]. In the arcuate nucleus of aging animals, decrease of NPY expression was detected, which coincided by an increase of CART expression [34]. However, similar change of CART peptide expression could not be detected in the NACC. Although CARTimmunoreactivity differed slightly in the NACC along with normal aging, the changes occurred in old animals were not statistically significant when compared to younger or middle-aged adult rats.

As we have demonstrated, CART-immunoreactivity in the NACC was due to CART-immunoreactive neurons and neuronal processes including terminals of local and long projecting axons. CART axon terminals are mostly originate from local axon collaterals of neurons of the NACC, whereas small proportion of axons are coming from CART-immunoreactive cell bodies of the perifornical area of the lateral hypothalamus as well as of the arcuate and amygdala nuclei [35]. Among these regions, alteration of CART expression during aging has been shown only in the arcuate nucleus [34]. CART-immunopositive neuronal somata in the NACC are densely innervated by dopaminergic axon terminals mostly coming from the VTA, another brain area that regulates feeding behavior [27, 30]. Concerning the dopamine signal in the NACC of elderly animals, decreased binding to dopaminergic receptors and lower basal extracellular dopamine release were measured indicating age-related change in the VTA $[9,36]$. Since injection of D3 dopamine receptor agonists lowers levels of CART mRNA in the NACC [11], decreased dopamine signaling in the aged animals would reasonably increase CART expression. However, based on CARTdopamine interaction, a homeostatic function of CART peptide in the NACC was suggested, which means that if dopamine signaling in the NACC increases, CART peptide is released and tends to oppose dopamine action [10]. According to this suggestion, the decreased dopamine signaling would result in the lack of the release of CART peptide from the neurons of the NACC, which indicate unchanged expression of CART peptide by NACC neurons. Considering that most axon terminals in the NACC belong to local axon-collaterals of its CART-immunoreactive neurons, the 
suggested homeostatic function of CART peptide in the NACC is a reasonable explanation to our results.

We have to note, however, that the unaltered CART expression does not inevitably mean unaltered effect of the CART peptide in the NACC. Thus, the precise determination of the role of CART peptide in the senescent anorexia needs further studies.

\section{ACKNOWLEDGEMENTS}

The authors thank dr. László Seress (Central Electron Microscopic Laboratory, Medical Faculty, University of Pécs, Pécs, Hungary) for reading and commenting the manuscript. This research was supported by the grant of the University of Pécs ÁOKKA-34039-4/2009 to H. A., and grant of the PTE-ETK Scientific Committee to S. A.

\section{REFERENCES}

1. Abraham, H., Covasa, M., Hajnal, A. (2009) Cocaine- and amphetamine-regulated transcript peptide immunoreactivity in the brain of the CCK-1 receptor deficient obese OLETF rat. Exp. Brain Res. 196, 545-556.

2. Akimoto-Takano, S., Sakurai, C., Kanai, S., Hosoya, H., Ohta, M., Miyasaka, K. (2005) Differences in the appetite-stimulating effect of orexin, neuropeptide $\mathrm{Y}$ and ghrelin among young, adult and old rats. Neuroendocrinology 82, 256-263.

3. Armbruszt, S., Abraham, H., Figler, M., Kozicz, T., Hajnal, A. (2013) Cocaine- and amphetamineregulated transcript (CART) peptide immunoreactivity in feeding- and reward-related areas of young OLETF rats. J. Chem. Neuroanat. 50-51, 75-84.

4. Balaskó, M., Soós, S., Párniczky, A., Koncsecskó-Gáspár, M., Székely, M., Pétervári, E. (2012) Anorexic effect of peripheral cholecystokinin (CCK) varies with age and body composition (short communication). Acta Physiol. Hung. 99, 166-172.

5. Balasko, M., Rostas, I., Furedi, N., Miko, A., Tenk, J., Cseplo, P., Koncsecsko-Gaspar, M., Soos, S., Szekely, M., Petervari, E. (2013) Age and nutritional state influence the effects of cholecystokinin on energy balance. Exp. Gerontol. 48, 1180-1188.

6. Black, B. J. Jr., McMahan, C. A., Masoro, E. J., Ikeno, Y., Katz, M. S. (2003) Senescent terminal weight loss in the male F344 rat. Am. J. Physiol. Regul. Integr. Comp. Physiol. 284, R336-342.

7. Blanton, C. A., Horwitz, B. A., Murtagh-Mark, C., Gietzen, D. W., Griffey, S. M., McDonald, R. B. (1998) Meal patterns associated with the age-related decline in food intake in the Fischer 344 rat. Am. J. Physiol. 275, R1494-1502.

8. Blanton, C. A., Horwitz, B. A., Blevins, J. E., Hamilton, J. S., Hernandez, E. J., McDonald, R. B. (2001) Reduced feeding response to neuropeptide Y in senescent Fischer 344 rats. Am. J. Physiol. Regul. Integr. Comp. Physiol. 280, R1052-1060.

9. Diao, L. H., Bickford, P. C., Stevens, J. O., Cline, E. J., Gerhardt, G. A. (1997) Caloric restriction enhances evoked DA overflow in striatum and nucleus accumbens of aged Fischer 344 rats. Brain Res. 763, 276-280.

10. Hubert, G. W., Jones, D. C., Moffett, M. C., Rogge, G., Kuhar, M. J. (2008) CART peptides as modulators of dopamine and psychostimulants and interactions with the mesolimbic dopaminergic system. Biochem. Pharmacol. 75, 57-62.

11. Hunter, R. G., Jones, D., Vicentic, A., Hue, G., Rye, D., Kuhar, M. J. (2006) Regulation of CART mRNA in the rat nucleus accumbens via D3 dopamine receptors. Neuropharmacology 50, 858-864.

12. Jernigan, T. L., Archibald, S. L., Fennema-Notestine, C., Gamst, A. C., Stout, J. C., Bonner, J., Hesselink, J. R. (2001) Effects of age on tissues and regions of the cerebrum and cerebellum. Neurobiol. Aging 22, 581-594. 
13. Kaneda, T., Makino, S., Nishiyama, M., Asaba, K., Hashimoto, K. (2001) Differential neuropeptide responses to starvation with ageing. J. Neuroendocrinol. 13, 1066-1075.

14. Kappeler, L., Gourdji, D., Zizzari, P., Bluet-Pajot, M. T., Epelbaum, J. (2003) Age-associated changes in hypothalamic and pituitary neuroendocrine gene expression in the rat. J. Neuroendocrinol. 15, 592-601.

15. Kessler, B. A., Stanley, E. M., Frederick-Duus, D., Fadel, J. (2011) Age-related loss of orexin/hypocretin neurons. Neuroscience 178, 82-88.

16. Koylu, E. O., Couceyro, P. R., Lambert, P. D., Ling, N. C., DeSouza, E. B., Kuhar, M. J. (1997) Immunohistochemical localization of novel CART peptides in rat hypothalamus, pituitary and adrenal gland. J. Neuroendocrinol. 9, 823-833.

17. Koylu, E. O., Couceyro, P. R., Lambert, P. D., Kuhar, M. J. (1998) Cocaine- and amphetamine-regulated transcript peptide immunohistochemical localization in the rat brain. J. Comp. Neurol. 391 115-132.

18. Lambert, P. D., Couceyro, P. R., McGirr, K. M., Dall Vechia, S. E., Smith, Y., Kuhar, M. J. (1998) CART peptides in the central control of feeding and interactions with neuropeptide Y. Synapse 29, 293-298.

19. Long, X., Liao, W., Jiang, C., Liang, D., Qiu, B., Zhang, L. (2012) Healthy aging: an automatic analysis of global and regional morphological alterations of human brain. Acad. Radiol. 1978519793.

20. McDonald, R. B., Florez-Duquet, M., Murtagh-Mark, C., Horwitz, B. A. (1996) Relationship between cold-induced thermoregulation and spontaneous rapid body weight loss of aging F344 rats. Am. J. Physiol. Regul. Integr. Comp. Physiol. 271, R1115-R1122.

21. Orsi, G., Perlaki, G., Kovacs, N., Aradi, M., Papp, Z., Karadi, K., Szalay, C., Karadi, Z., Lenard, L., Tenyi, T., Plozer, E., Gabriel, R., Nagy, F., Doczi, T., Komoly, S., Jokeit, H., Schwarcz, A., Janszky, J. (2011) Body weight and the reward system: the volume of the right amygdala may be associated with body mass index in young overweight men. Brain Imaging Behav. 5, 149-157.

22. Paxinos, G., Watson, C. (1982) The Rat Brain in Stereotaxic Coordinates. Academic Press Australia, Sydney.

23. Pereira, P. A., Santos, D., Neves, J., Madeira, M. D., Paula-Barbosa, M. M. (2013) Nerve growth factor retrieves neuropeptide $\mathrm{Y}$ and cholinergic immunoreactivity in the nucleus accumbens of old rats. Neurobiology of Aging 34, 1988-1995.

24. Pétervári, E., Balaskó, M., Garami, A., Soós, S., Székely, M. (2009) Suppression of food intake by intracerebroventricular injection of alpha-MSH varies with age in rats. Acta Physiol. Hung. 96, 483-487.

25. Petervari, E., Garami, A., Soos, S., Szekely, M., Balasko, M. (2010) Age-dependence of alpha-MSHinduced anorexia. Neuropeptides 44, 315-322.

26. Porkka-Heiskanen, T., Alanko, L., Kalinchuk, A., Heiskanen, S., Stenberg, D. (2004) The effect of age on prepro-orexin gene expression and contents of orexin A and B in the rat brain. Neurobiol. Aging 25, 231-238.

27. Smith, Y., Koylu, E. O., Couceyro, P., Kuhar, M. J. (1997) Ultrastructural localization of CART (cocaine- and amphetamine-regulated transcript) peptides in the nucleus accumbens of monkeys. Synapse 27, 90-94.

28. Sohn, E. H., Wolden-Hanson, T., Matsumoto, A. M. (2002) Testosterone (T)-induced changes in arcuate nucleus cocaine-amphetamine-regulated transcript and NPY mRNA are attenuated in old compared to young male brown Norway rats: contribution of $\mathrm{T}$ to age-related changes in cocaine-amphetamine-regulated transcript and NPY gene expression. Endocrinology 143, 954-963.

29. Takano, S., Kanai, S., Hosoya, H., Ohta, M., Uematsu, H., Miyasaka, K. (2004) Orexin-A does no stimulate food intake in old rats. Am. J. Physiol. Gastrointest. Liver Physiol. 287, 1182-1187.

30. Upadhya, M. A., Nakhate, K. T., Kokare, D. M., Singh, U., Singru, P. S., Subhedar, N. K. (2012) CART peptide in the nucleus accumbens shell acts downstream to dopamine and mediates the reward and reinforcement actions of morphine. Neuropharmacology 62, 1823-1833. 
31. Vicentic, A., Dominguez, G., Hunter, R. G., Philpot, K., Wilson, M., Kuhar, M. J. (2004) Cocaine- and amphetamine-regulated transcript peptide levels in blood exhibit a diurnal rhythm: regulation by glucocorticoids. Endocrinology 145, 4119-4124.

32. Volkoff, H., Peter, R. E. (2000) Effects of CART peptides on food consumption, feeding and associated behaviors in the goldfish, Carassius auratus: actions on neuropeptide Y- and orexin A-induced feeding. Brain Res. 887, 125-133.

33. Walhovd, K. B., Westlye, L. T., Amlien, I., Espeseth, T., Reinvang, I., Raz, N., Agartz, I., Salat, D. H., Greve, D. N., Fischl, B., Dale, A. M., Fjell, A. M. (2011) Consistent neuroanatomical age-related volume differences across multiple samples. Neurobiol. Aging 32, 916-932.

34. Wolden-Hanson, T., Marck, B. T., Matsumoto, A. M. (2004) Blunted hypothalamic neuropeptide gene expression in response to fasting, but preservation of feeding responses to AgRP in aging male Brown Norway rats. Am. J. Physiol. Regul. Integr. Comp. Physiol. 287, R138-R146.

35. Yang, S. C., Shieh, K. R., Li, H. Y. (2005) Cocaine- and amphetamine-regulated transcript in the nucleus accumbens participates in the regulation of feeding behavior in rats. Neuroscience 133, 841-851.

36. Yoshimoto, K., Kato, B., Ueda, S., Noritake, K., Sakai, K., Shibata, M., Hori, M., Kawano, H., Takeuchi, Y., Wakabayashi, Y., Yasuhara, M. (2001) Dopamine and serotonin uptake inhibitors on the release of dopamine and serotonin in the nucleus accumbens of young and aged rats. Mech. Ageing Dev. 122, 1707-1721. 